\title{
Tables of the Roots of the Associated Legendre Function with Respect to the Degree
}

\author{
By Helmut F. Bauer
}

\begin{abstract}
Tables of the numerical value of the roots with respect to the degree of the Legendre functions of the first kind and those of the first derivative are presented.
\end{abstract}

Determination of the Roots. In a large number of physical and engineering problems involving conical boundaries, the roots with respect to the degree of the associated Legendre function or those of its first derivative are of importance. Liquid oscillations in a conical container [1], wave propagation in conical horns [2], [3], heat and mass transport in conical systems [4], and many other problems require knowledge of these roots. For the associated Legendre function, as well as for its first derivative, there exists an infinite number of simple roots with respect to the degree. Some of these roots have been given by Pal [5] and later by Bauer [6], who presented better accuracy and found, in addition, that Pal did not detect for $m \geqslant 1$ the lowest root with respect to the degree of the first derivative of the associated Legendre function. In the following tables (see the supplements section at the end of this issue), the roots of $P_{\lambda}^{m}(\cos \alpha)=0$ (Tables 1.1 through 1.35) and those of $\partial P_{\lambda}^{m} / \partial \alpha=0$ (Tables 2.1 through 2.35) are presented for integer $m$ and given $\alpha$, ranging from $5^{\circ}$ in steps of $5^{\circ}$ to $175^{\circ}$. From the representation of the associated Legendre function as a hypergeometric series, i.e.,

$P_{\lambda}^{m}(\cos \alpha)=\frac{(-1)^{m} \Gamma(m+\lambda+1) \sin ^{m} \alpha}{2^{m} m ! \Gamma(\lambda-m+1)}{ }_{2} F_{1}\left(1+m+\lambda, m-\lambda, 1+m ; \frac{1}{2}(1-\cos \alpha)\right)$

one obtains, after introducing the hypergeometric function ${ }_{2} F_{1}$ as an infinite series, the equation

$$
\sum_{n=0}^{\infty} \frac{(m+\lambda+1)_{n}(m-\lambda)_{n} m !}{n !(m+n) !} \sin ^{2 n}\left(\frac{\alpha}{2}\right)=0
$$

for the determination of the zeros $\lambda_{m n}$ of $P_{\lambda}^{m}(\cos \alpha)=0$ (Tables 1.1-1.35). In this equation the Pochhammer symbol $(a)_{n}=a(a+1)(a+2) \cdots(a+n-1),(a)_{0}=1$ has been used. For the determination of the roots of the first derivative of the associated Legendre function

$$
\frac{d}{d \alpha}\left[P_{\lambda^{\prime}}^{m}(\cos \alpha)\right]=0
$$

Received April 6, 1984; revised May 22, 1985.

1980 Mathematics Subject Classification. Primary 33A45, Secondary 65A05, 65H05. 
one obtains with the recurrence formula

$$
\left(1-x^{2}\right) \frac{d P_{\lambda^{\prime}}^{m}}{d x}=\left(\lambda^{\prime}+m\right) P_{\lambda^{\prime}-1}^{m}(x)-\lambda^{\prime} x P_{\lambda^{\prime}}^{m}(x)
$$

an equation of the form

$$
\begin{gathered}
{\left[\lambda^{\prime}-m-\lambda^{\prime} \cos \alpha\right]+\sum_{n=1}^{\infty} \frac{m !\left(m+\lambda^{\prime}+1\right)_{n-1}\left(m-\lambda^{\prime}+1\right)_{n-1}}{n !(n+m) !} \sin ^{2 n}\left(\frac{\alpha}{2}\right)} \\
\times\left[\left(\lambda^{\prime 2}-m^{2}\right)\left(m-\lambda^{\prime}+n\right)-\lambda^{\prime}\left(m-\lambda^{\prime}\right)\left(m+n+\lambda^{\prime}\right) \cos \alpha\right]=0
\end{gathered}
$$

(Tables 2.1-2.35)

From these equations (1) and (2), the roots $\lambda_{m n}$ and $\lambda_{m n}^{\prime}$ have been obtained respectively for the above given values of $\alpha$, where for each $m=0,1,2,3,4,5$ the first ten roots $(n=1,2, \ldots, 10)$ are presented. The roots have been obtained by the regula falsi method. The accuracy of the roots is $10^{-8}$, but they were rounded to four digits. Their value was always introduced into the function and led always to values of less than $10^{-10}$.

It may be mentioned that reference [6] contains a bibliography of tables of Legendre functions, and that to these references more recent ones [7], [8], [9], should be added.

University of the German Armed Forces

Werner-Heisenberg-Weg 39

8014 Neubiberg, West Germany

1. H. F. Bauer, "Flüssigkeitsschwingungen in Kegelbehälterformen," Acta Mech., v. 43, 1982, pp. 185-200.

2. H. Buchноцz, "Die Bewegung elektromagnetischer Wellen in einem kegelförmigen Horn," Ann. Physik, v. 37, Heft 3, 1940, pp. 173-225.

3. H. Buснноцz, "Das Schallfeld in einem Kegelhorn unter verschiedenen Anfangsbedingungen," Akust. Z., v. 5, Heft 4, 1940, pp. 169-189.

4. H. S. Carslaw \& J. C. Jaeger, Conduction of Heat in Solids, Clarendon Press, Oxford, 1959.

5. B. PAL, "On the numerical calculation of the roots of the equations $P_{n}^{m}(\mu)=0$ and $d P_{n}^{m}(\mu) / d \mu=0$ regarded as equations in $n$," Bull. Calcutta Math. Soc., Part I, v. 9, 1917, pp. 85-95; Part II, v. 10, 1918, pp. 187-194.

6. H. F. BAUER, "On the numerical value of the roots of the associated Legendre function with respect to the order," Z. Angew. Math. Mech., v. 61, 1981, pp. 525-527.

7. J. M. SMith, F. W. J. Olver \& D. W. Lozier, "Extended-range arithmetic and normalized Legendre polynomials," ACM Trans. Math. Software, v. 7, 1981, pp. 93-105.

8. D. W. Lozier \& J. M. SMiTh, "Algorithm 567. Extended-range arithmetic and normalized Legendre polynomials,” ACM Trans. Math. Software, v. 7, 1981, pp. 141-146.

9. F. W. J. Olver \& J. M. Sмiтh, “Associated Legendre functions on the cut," J. Comput. Phys., v. 51, 1983, pp. 502-518. 


\title{
Supplement to \\ Table of the Roots of the Associated Legendre Function with Respect to the Degree
}

\author{
By Helmut F. Bauer
}

\begin{tabular}{|c|c|c|c|c|c|c|}
\hline$m$ & 0 & 1 & 2 & 3 & 4 & 5 \\
\hline $\begin{array}{r}1 \\
2 \\
3 \\
4 \\
5 \\
6 \\
7 \\
8 \\
9 \\
10\end{array}$ & $\begin{array}{r}27.0558 \\
62.7548 \\
98.6640 \\
134.6207 \\
170.5955 \\
206.5789 \\
242.5673 \\
278.5586 \\
314.5519 \\
350.5466\end{array}$ & $\begin{array}{r}43.4110 \\
79.8943 \\
116.0804 \\
152.1791 \\
188.2402 \\
224.2817 \\
260.3118 \\
296.3346 \\
332.3525 \\
368.3669\end{array}$ & $\begin{array}{r}58.3605 \\
95.9610 \\
132.6583 \\
169.0528 \\
205.3074 \\
241.4855 \\
277.6172 \\
313.7186 \\
349.7991 \\
385.8645\end{array}$ & $\begin{array}{r}72.6312 \\
111.3661 \\
148.6530 \\
185.4151 \\
221.9221 \\
258.2847 \\
294.5572 \\
330.7697 \\
366.9401 \\
403.0799\end{array}$ & $\begin{array}{r}86.4862 \\
126.3129 \\
164.2131 \\
201.3771 \\
238.1701 \\
274.7472 \\
311.1870 \\
347.5337 \\
383.8141 \\
420.0458\end{array}$ & $\begin{array}{l}100.0549 \\
140.9192 \\
179.4337 \\
217.0153 \\
254.1134 \\
290.9244 \\
327.5495 \\
364.0467 \\
400.4522 \\
436.7893\end{array}$ \\
\hline
\end{tabular}

Table 1.1: Roots $\lambda_{\mathrm{mn}}$ of associated Legendre Functions with respect to the degree for $\alpha=5^{\circ}$

$a=10^{\circ}$

\begin{tabular}{|r|r|r|r|r|r|r|}
\hline$m$ & 0 & 1 & 2 & \multicolumn{1}{|c|}{4} & 4 & 5 \\
\hline 1 & 13.2756 & 21.4598 & 28.9462 & 36.0956 & 43.0385 & 49.8392 \\
2 & 31.1264 & 39.6995 & 47.7402 & 55.4527 & 62.9376 & 70.2535 \\
3 & 49.0814 & 57.7918 & 66.0862 & 74.0912 & 31.3305 & 89.5013 \\
4 & 67.0599 & 75.8408 & 84.2819 & 92.4693 & 100.4581 & 108.2862 \\
5 & 85.0474 & 93.8711 & 102.4083 & 110.7209 & 118.8516 & 126.8311 \\
6 & 103.0392 & 111.8917 & 120.4967 & 128.9008 & 137.1380 & 145.2335 \\
7 & 121.0334 & 129.9066 & 138.5620 & 147.0360 & 155.3562 & 163.5436 \\
8 & 139.0291 & 147.9180 & 156.6123 & 165.1415 & 173.5282 & 181.7904 \\
9 & 157.0253 & 165.9268 & 174.6522 & 183.2260 & 191.6673 & 199.9916 \\
10 & 175.0231 & 183.9340 & 192.6847 & 201.2954 & 209.7823 & 218.1588 \\
\hline
\end{tabular}

Table 1.2: Roots $\lambda_{\mathrm{mn}}$ of associated Legendre Functions with respect to the degree for $\alpha=10^{\circ}$

$$
\alpha=15^{\circ}
$$

\begin{tabular}{|c|r|r|r|r|r|r|}
\hline$m$ & 0 & 1 & 2 & 3 & \multicolumn{1}{|c|}{4} & \multicolumn{1}{c|}{5} \\
\hline 1 & 8.6812 & 14.1446 & 19.1486 & 23.9306 & 28.5764 & 33.1284 \\
2 & 20.5832 & 26.3023 & 31.6710 & 36.8237 & 41.8265 & 46.7180 \\
3 & 32.5535 & 38.3630 & 43.8987 & 49.2439 & 54.4471 & 59.5394 \\
4 & 44.5394 & 50.3952 & 56.0275 & 61.4927 & 66.8272 & 72.0559 \\
5 & 56.5312 & 62.4152 & 68.1106 & 73.6583 & 79.0862 & 84.4146 \\
6 & 68.5258 & 74.4287 & 80.1688 & 85.7767 & 91.2746 & 96.6794 \\
7 & 80.5220 & 86.4386 & 92.2118 & 97.8656 & 103.4182 & 108.8835 \\
8 & 92.5191 & 98.4460 & 104.2449 & 109.9350 & 115.5314 & 121.0459 \\
9 & 104.5170 & 110.4518 & 116.2711 & 121.9907 & 127.6230 & 133.1783 \\
10 & 116.5152 & 122.4565 & 128.2925 & 134.0363 & 139.6987 & 145.2884 \\
\hline
\end{tabular}

Table 1.3: Roots $\lambda_{\mathrm{mn}}$ of associated Legendre functions with respect to the degree for $\alpha=15^{\circ}$ 

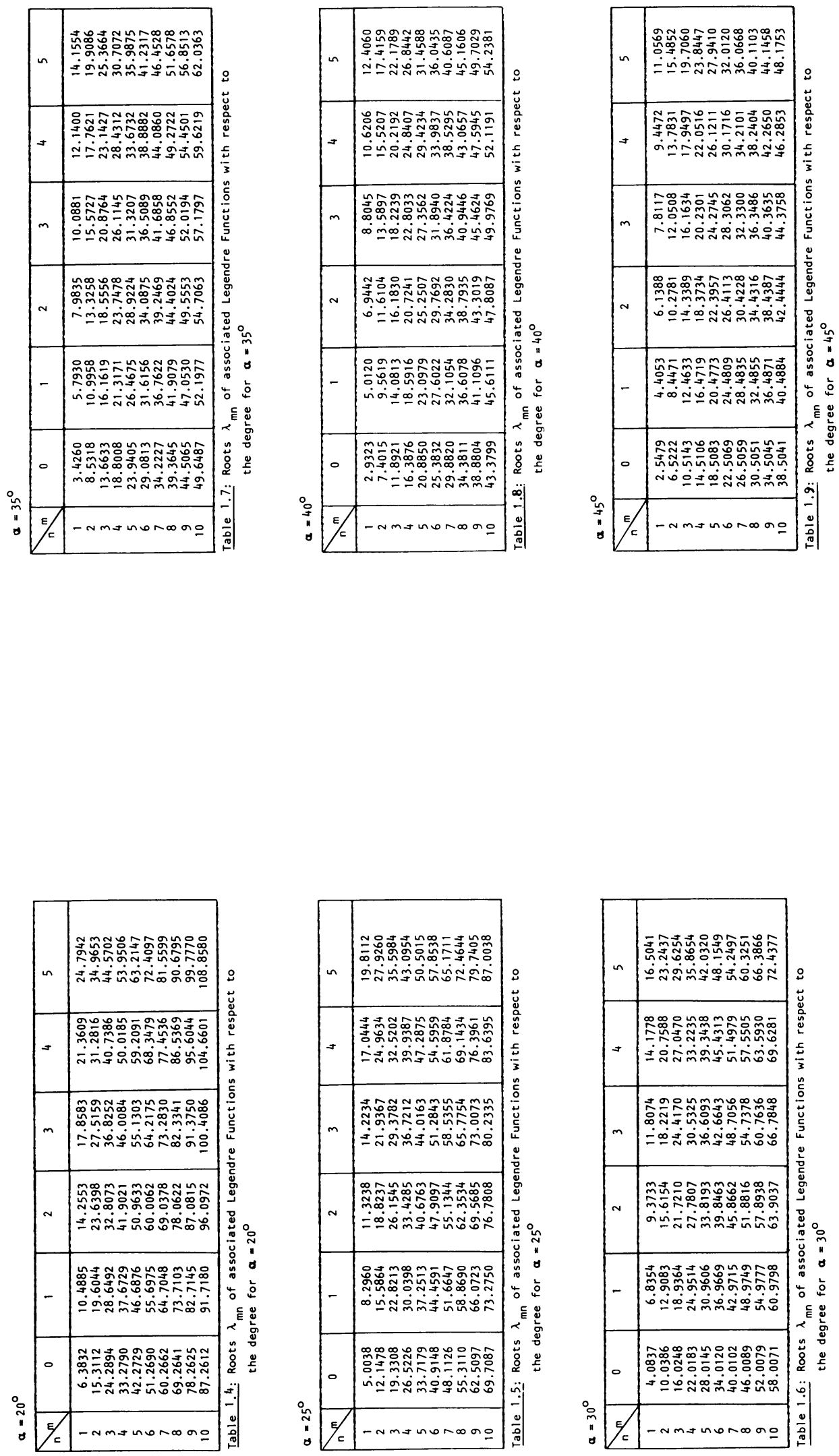

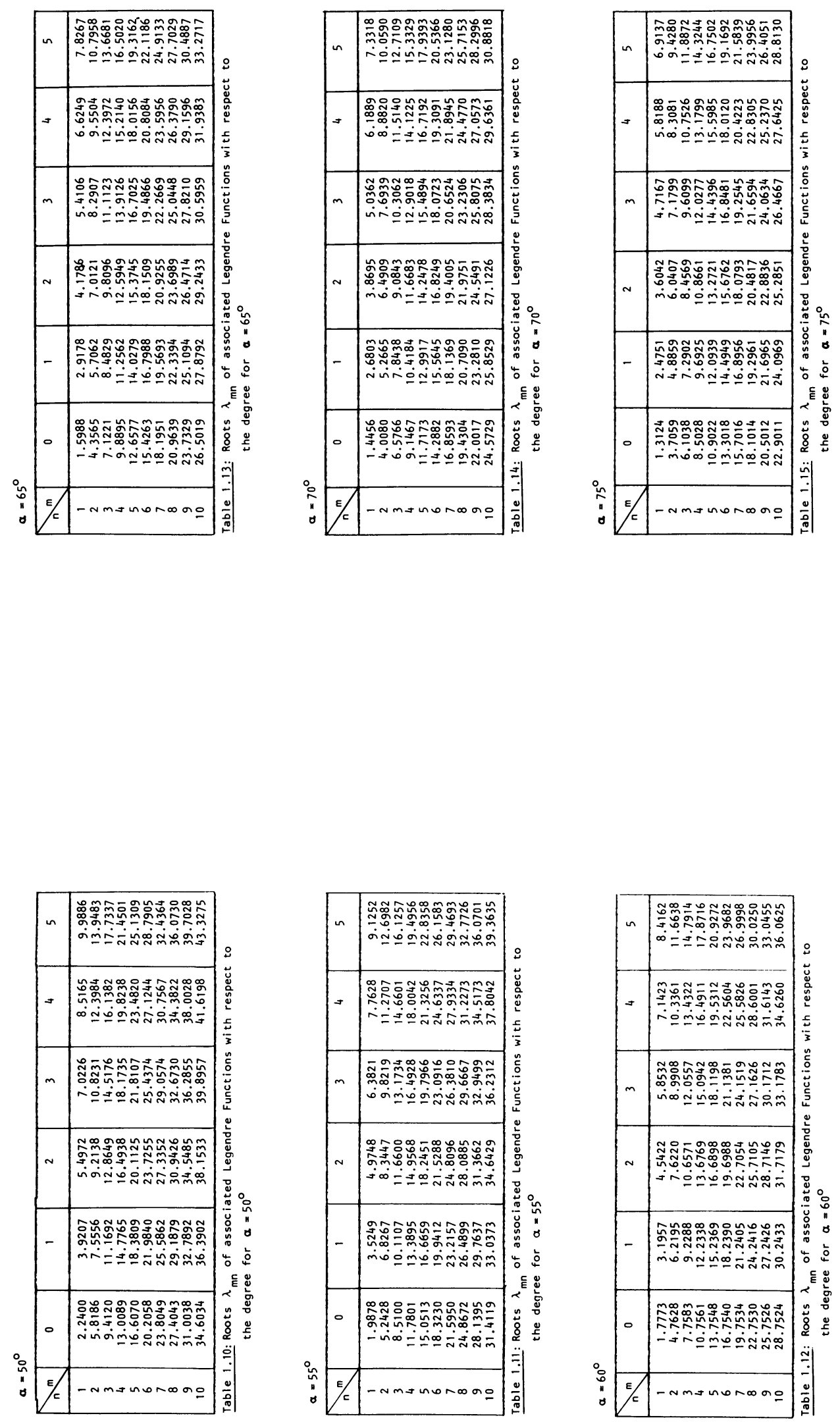

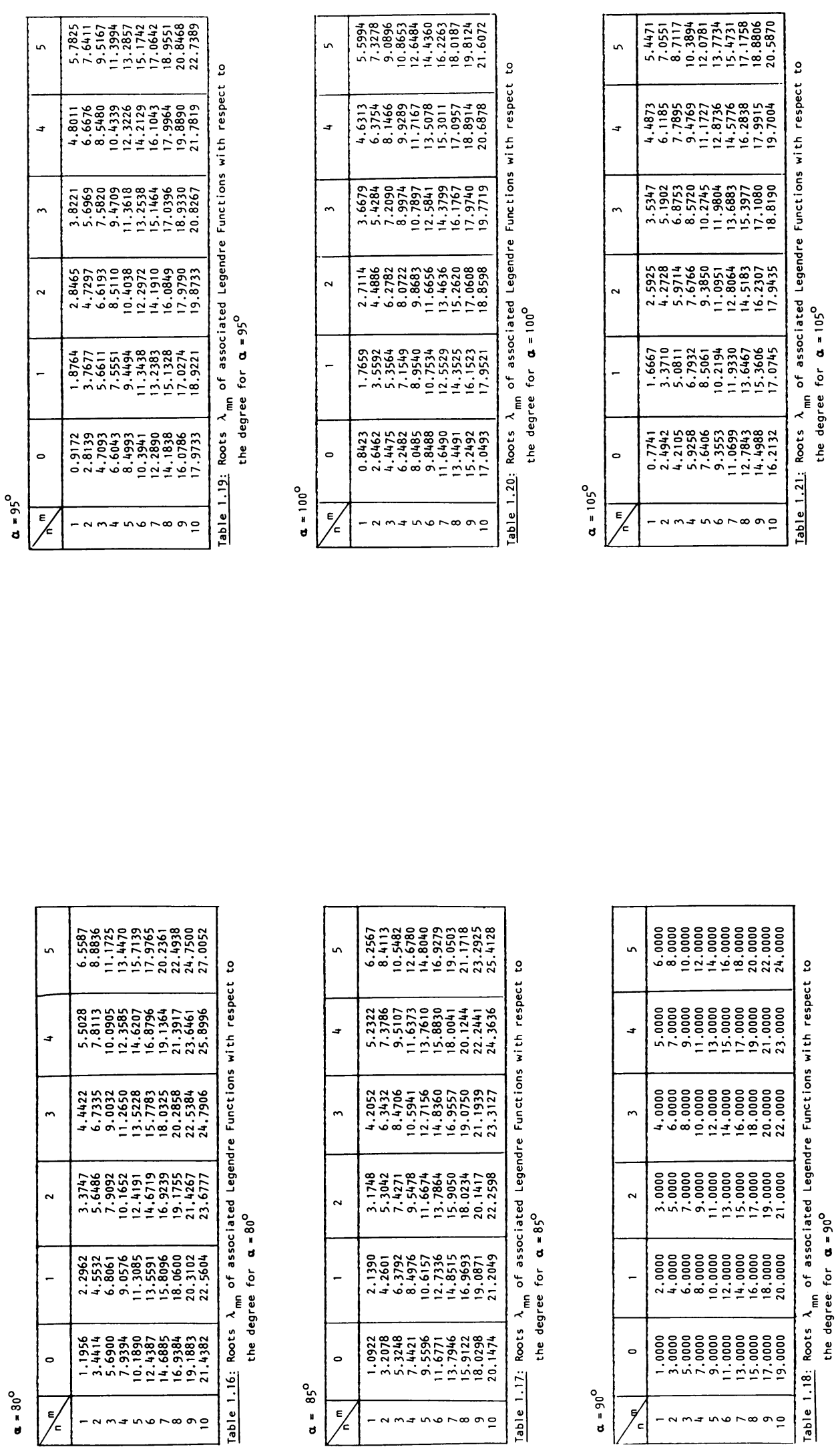

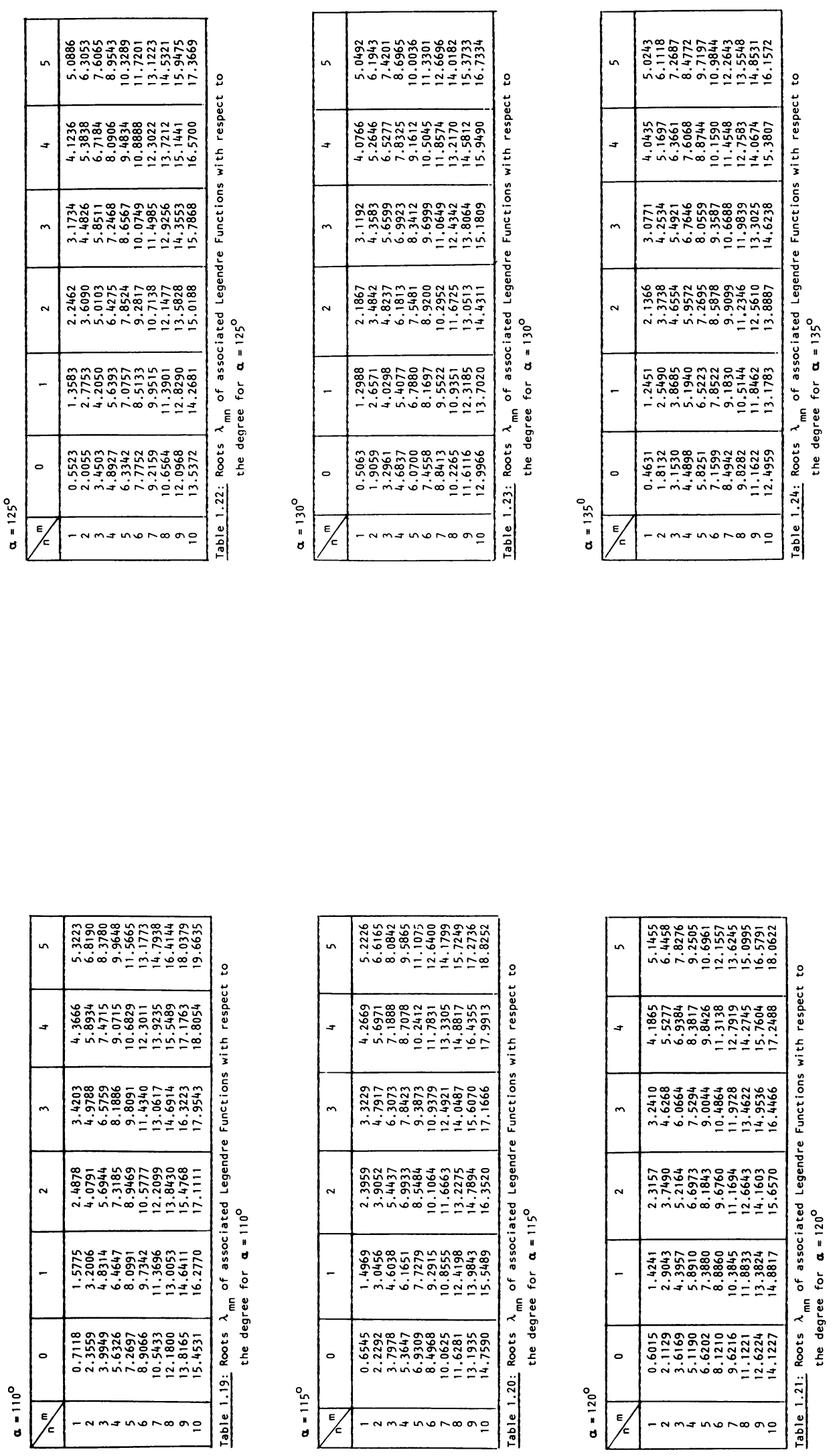

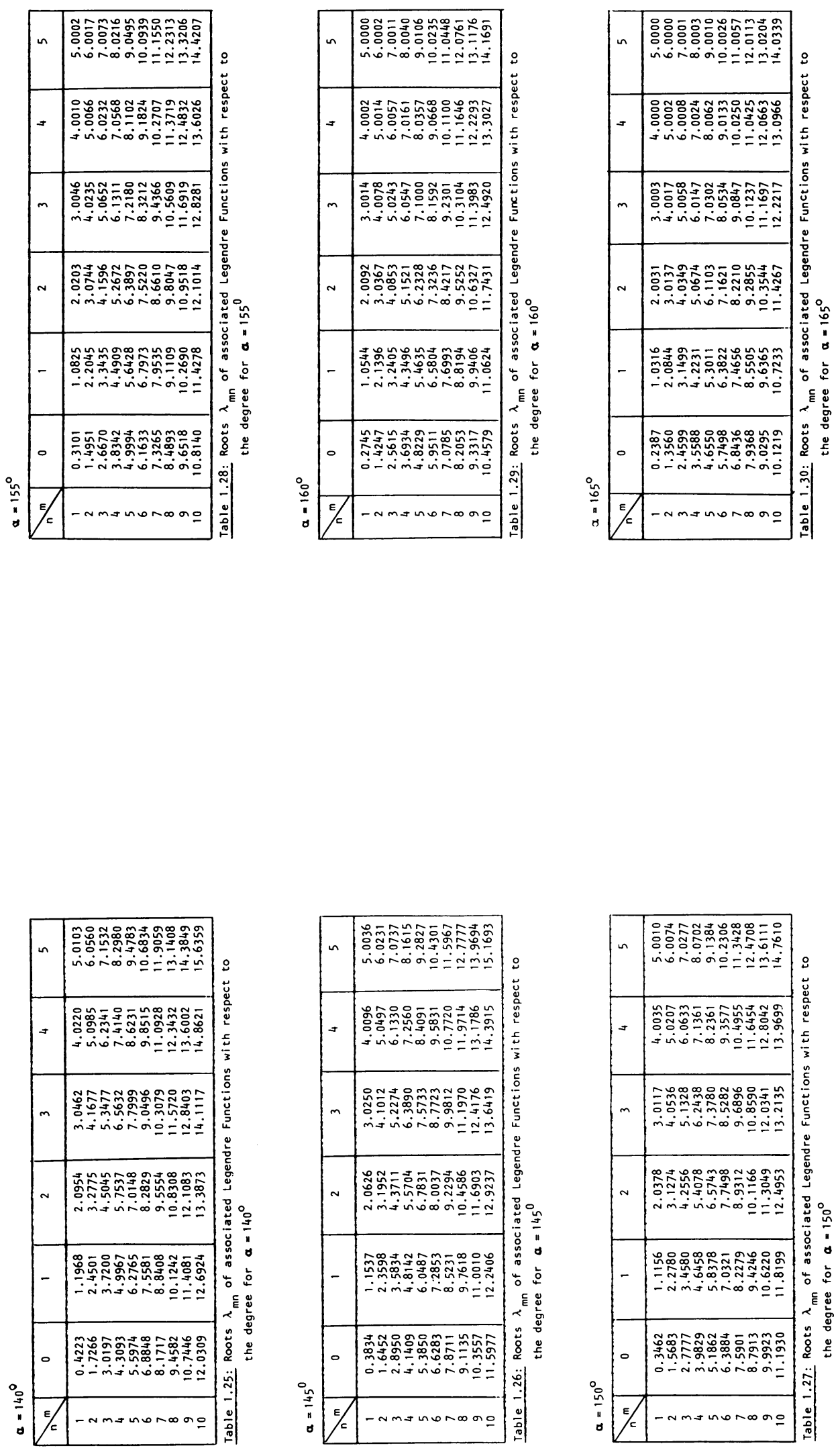

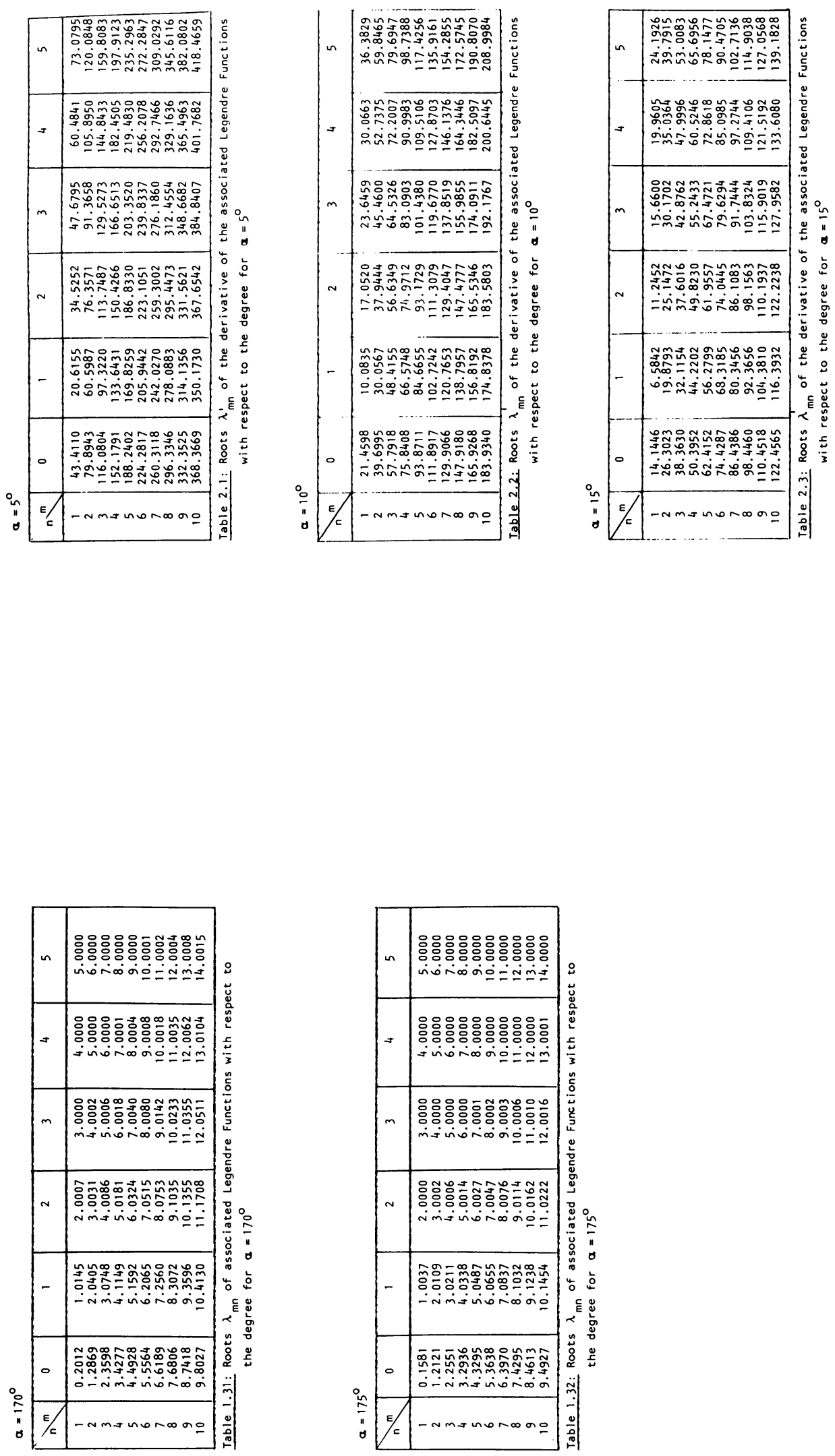

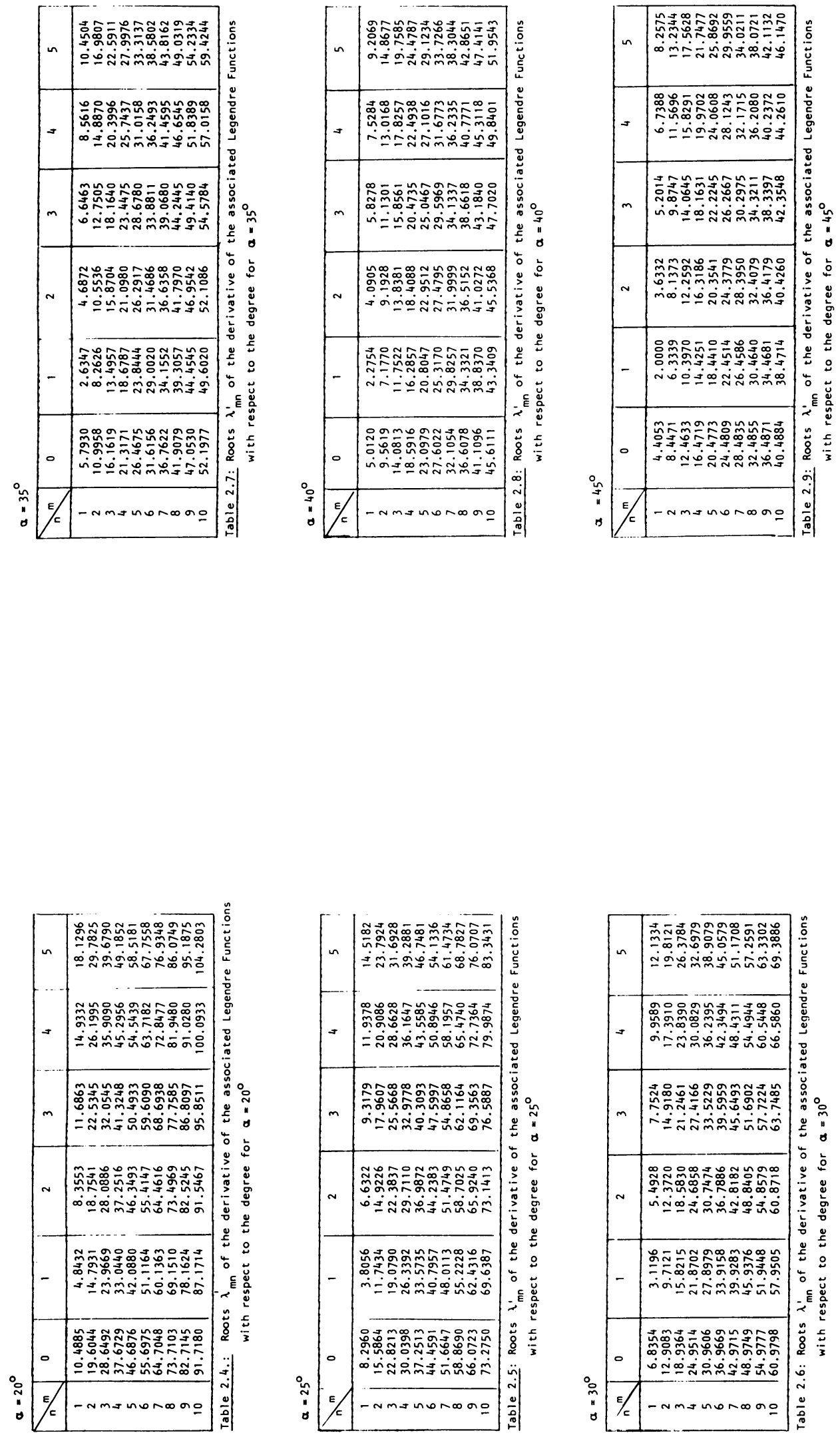

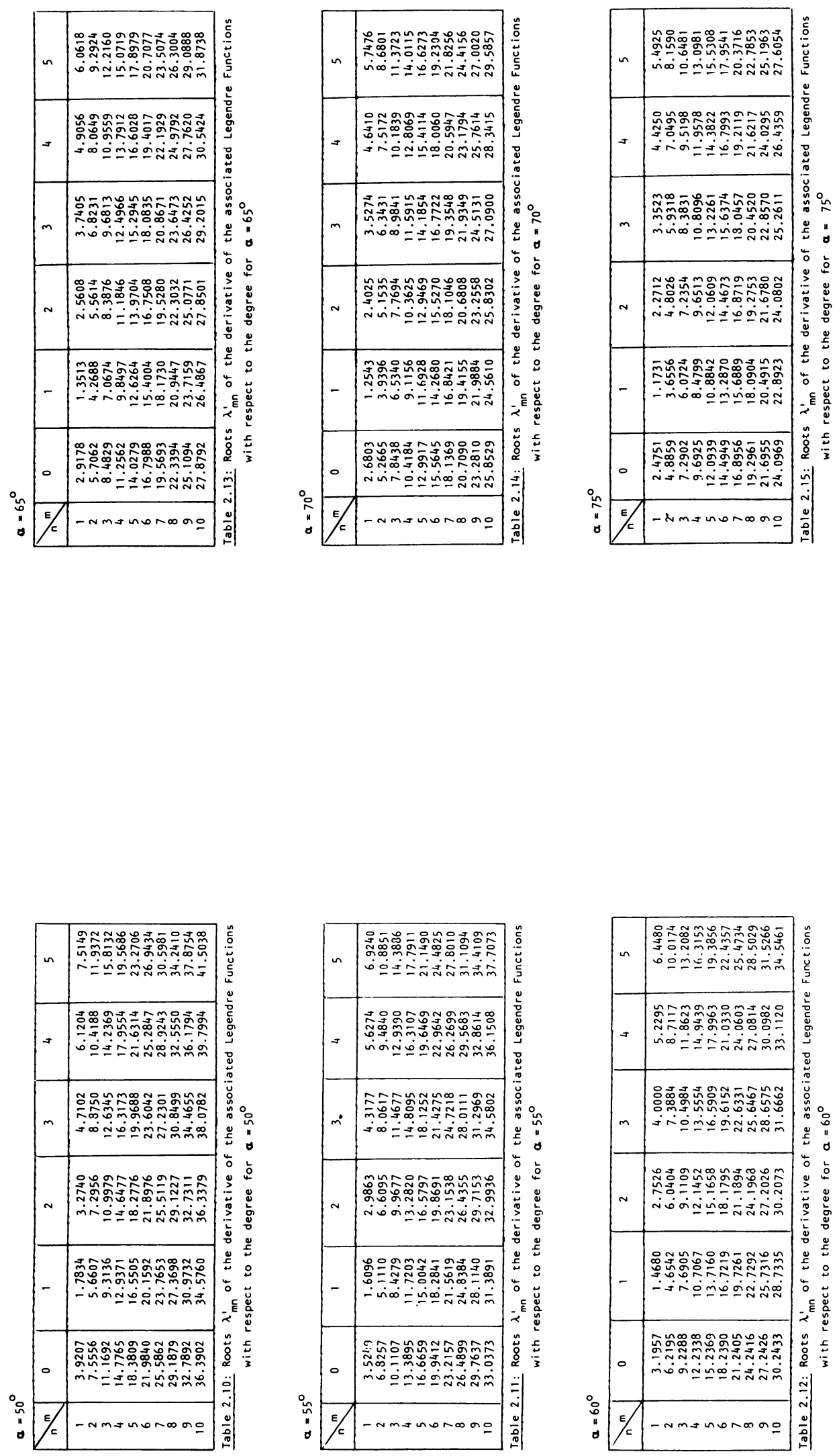

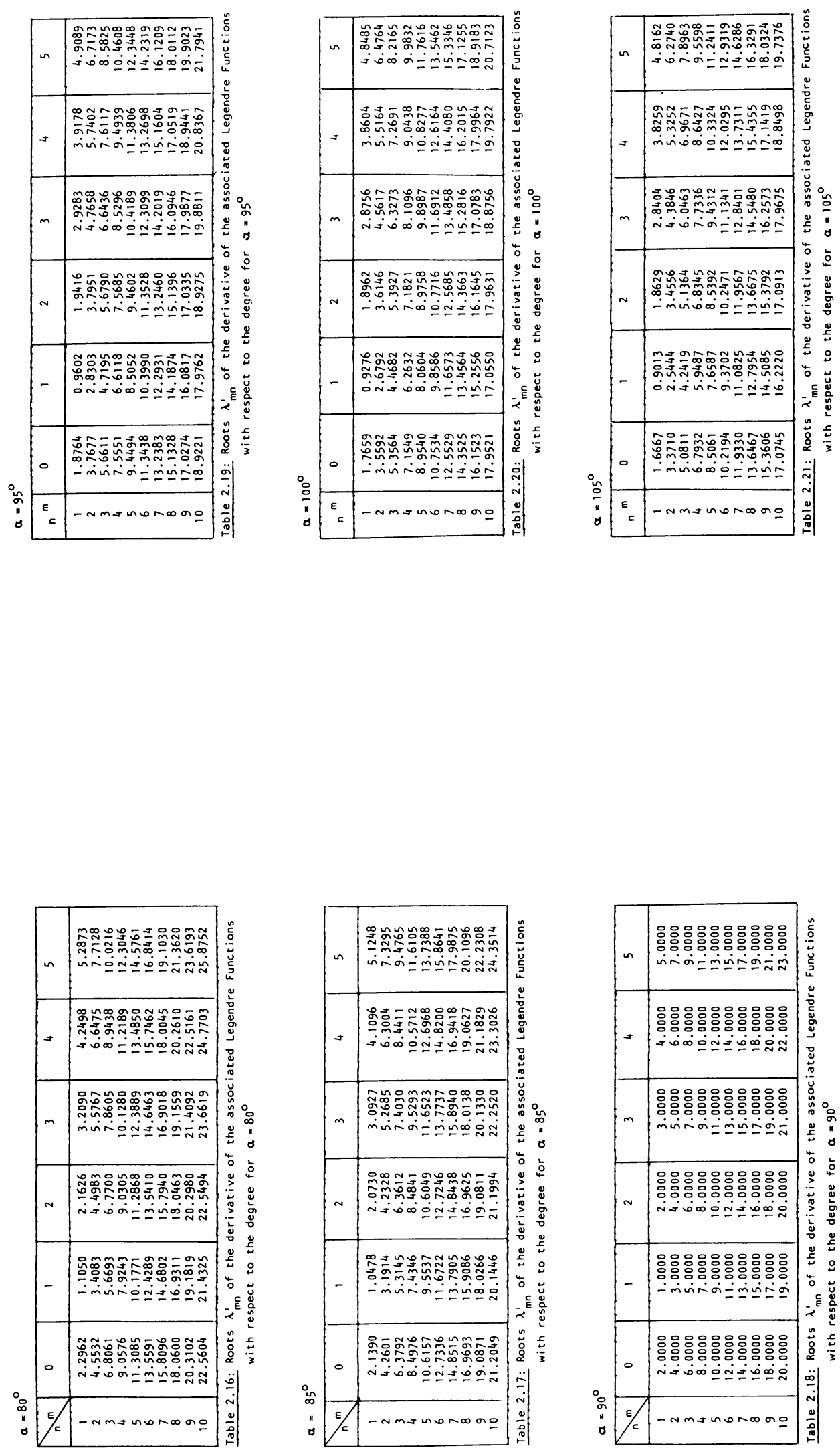

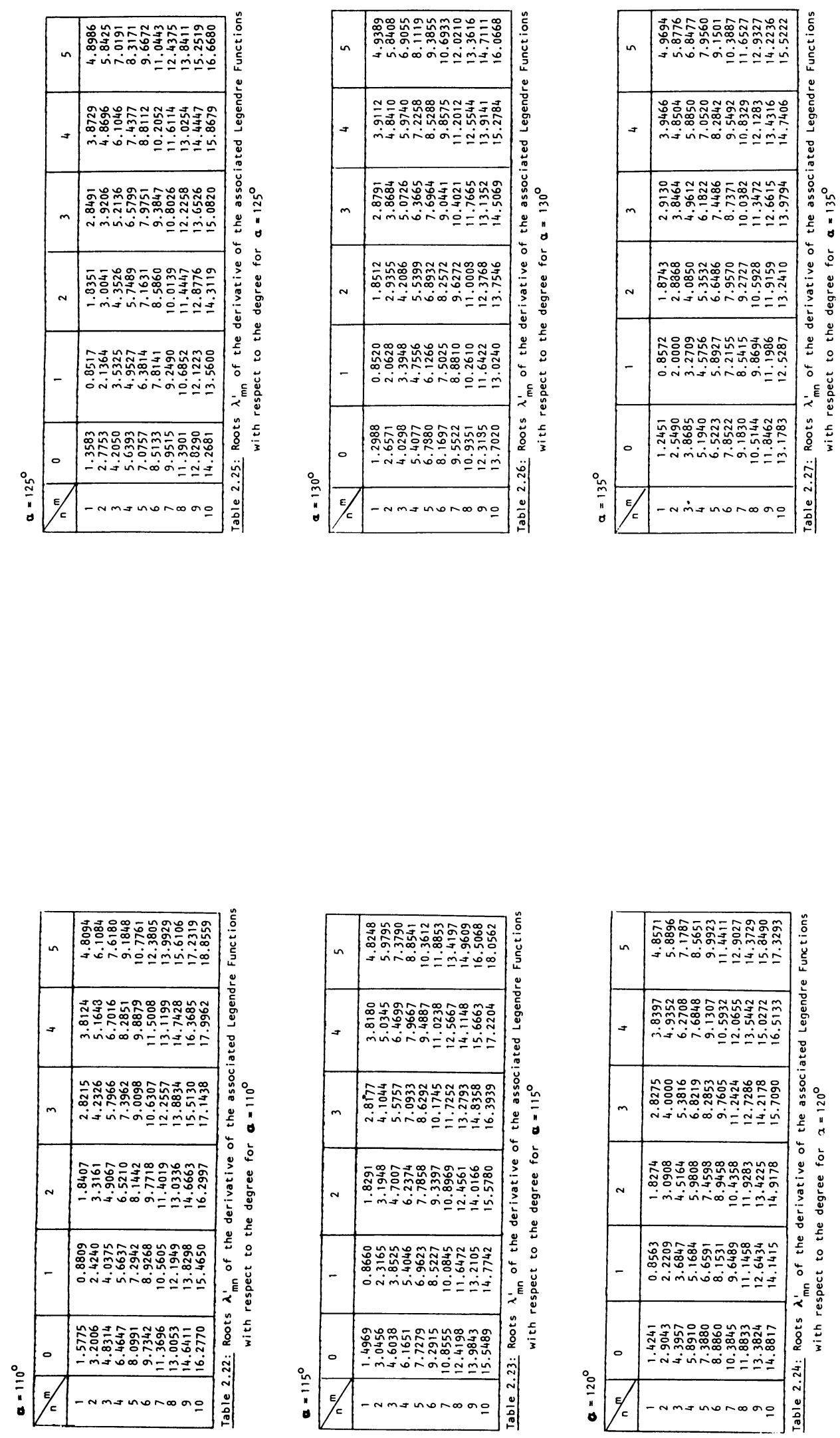

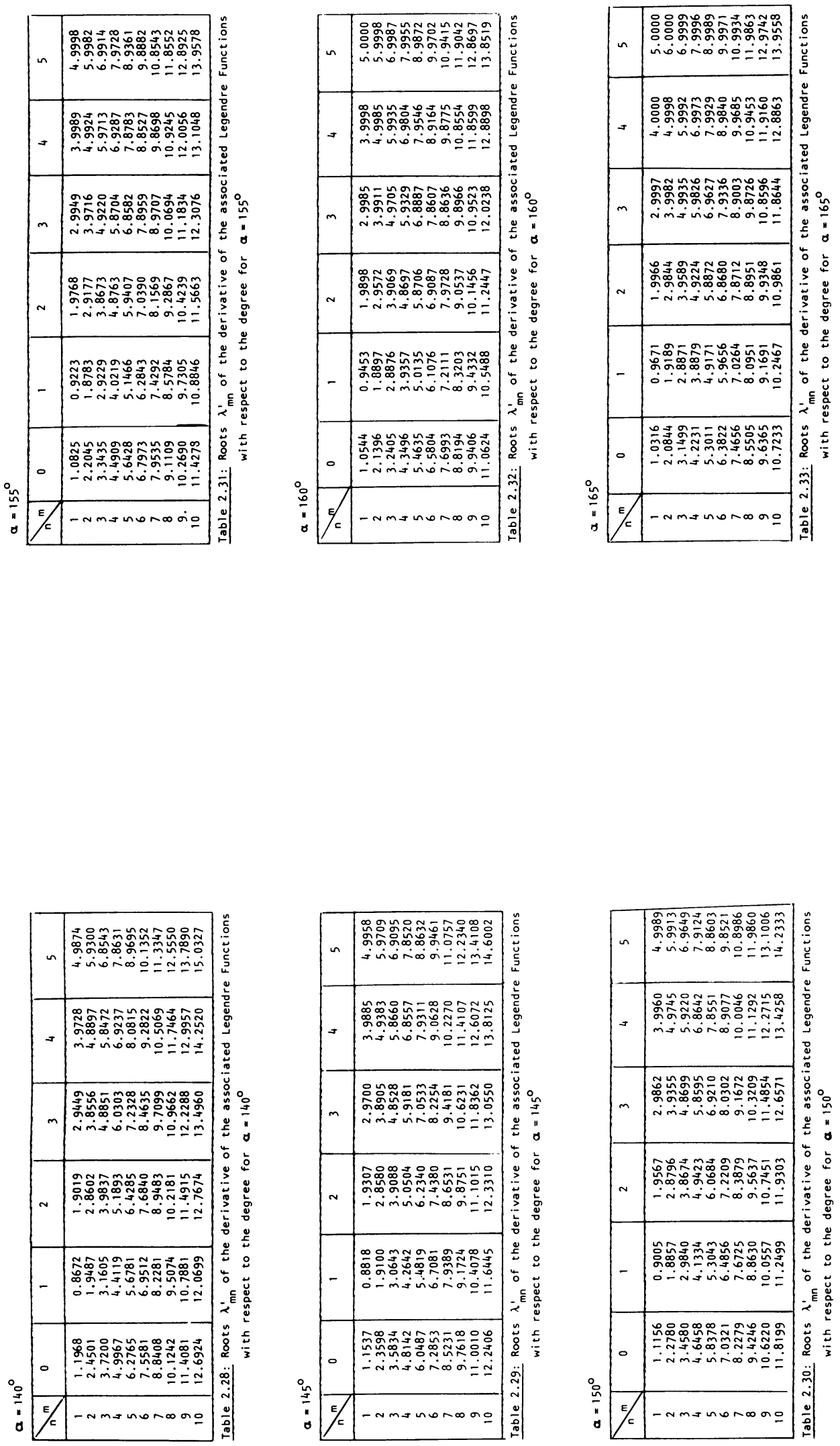

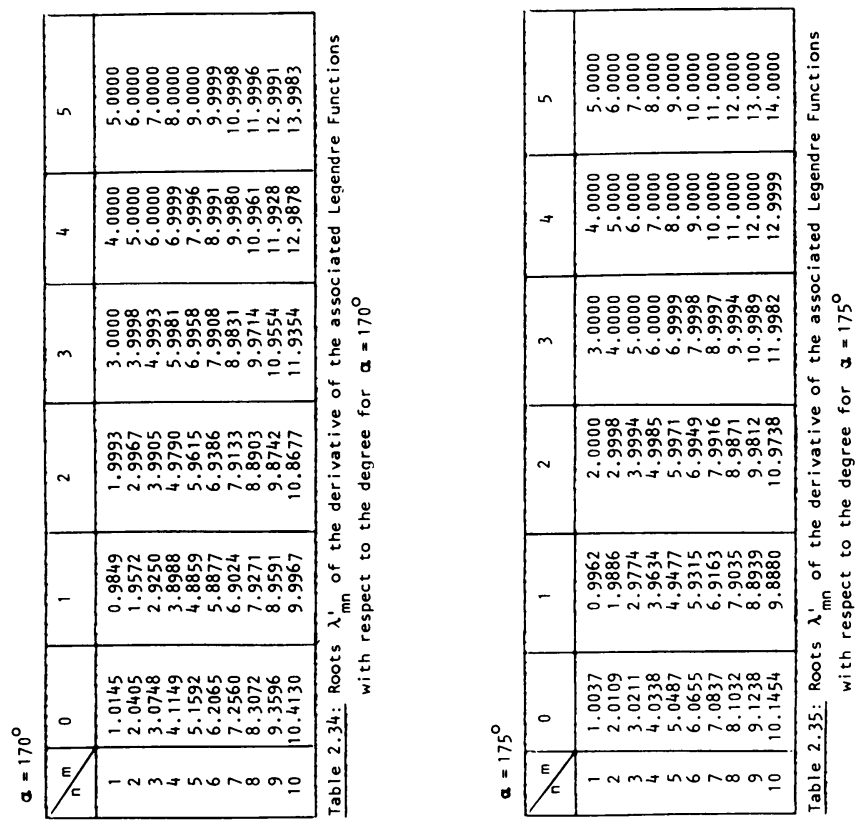